\title{
PENGUKURAN DENSITAS DAN DIAMETER POHON PULAI (Alstonia scholaris) DI TAMAN HUTAN RAYA SULTAN SYARIF HASYIM
}

\author{
The Density and Tree Diameter Measurement of Pulai (alstonia scholaris) at the Sultan \\ Syarif Hasyim City Forest Park \\ Sri Wahyuni \\ Fakultas Keguruan dan Ilmu Pendidikan Universitas Lancang Kuning \\ E-mail: sriwahyunifkip@unilak.ac.id
}

\begin{abstract}
ABSTRAK
Penelitian ini bertujuan untuk mengukur densitas dan diameter pohon pulai (Alstonia scholaris) di Taman Hutan Raya Sultan Syarif Hasyim Kota Pekanbaru. Data dikumpulkan dengan membuat plot pengamatan dengan intensitas sampling $0,1 \%$. Luas sampel $8.000 \mathrm{~m}^{2}$ yang terdiri dari 20 plot pengamatan berukuran $20 \mathrm{~m}$ x $20 \mathrm{~m}$. Penentuan plot pengamatan dengan menggunakan metode simple random sampling. Jenis data yang dikumpulkan adalah data primer yang terdiri dari densitas dan diameter pohon pulai serta data sekunder berupa peta dan informasi masyarakat setempat. Analisis data berupa kerapatan dan frekuensi spesies. Hasil analisis data dapat mengetahui densitas (kerapatan) dan diameter pohon pulai di Taman Hutan Raya Sultan Syarif Hasyim Kota Pekanbaru. Hasil penelitian adalah kerapatan (densitas) pohon pulai (Alstonia scholaris) di Tahura Sultan Syarif Hasyim Kota Pekanbaru adalah 18 batang/ 0,8 ha. Diameter rata-rata pohon pulai (Alstonia scholaris) di Tahura Sultan Syarif Hasyim Kota Pekanbaru adalah 35,12 cm.
\end{abstract}

Kata kunci : densitas, diameter, pulai

\section{ABSTRACT}

This study aims to measure the density and diameter of the pulai tree (Alstonia scholaris) in Sultan Syarif Hasyim Forest Park Pekanbaru. Data were collected by making observation plot with sampling intensity $0,1 \%$. The sample area is $8,000 \mathrm{~m}^{2}$ consisting of 20 observation plots measuring $20 \mathrm{~m} \times 20 \mathrm{~m}$. Determination of observation plot by using simple random sampling method. The types of data collected are primary data consisting of density and diameter of the pulai tree and secondary data in the form of maps and information of the local community. Data analysis of density and frequency of species. The results of data analysis can know the density and diameter of the pulai tree in the Sultan Syarif Hasyim Forest Park Pekanbaru. The result of research is density of pulai tree (Alstonia scholaris) in Tahura Sultan Syarif Hasyim Pekanbaru is 18 stems/ 0.8 ha. The average diameter of the pulai tree (Alstonia scholaris) in Tahura Sultan Syarif Hasyim Pekanbaru is $35.12 \mathrm{~cm}$.

Keywords: density, diameter, pulai

Diterima : 17 January 2020. Disetujui: 4 Februari 2020

\section{PENDAHULUAN}

Hutan merupakan suatu ekosistem yang mempunyai keanekaragaman flora dan faunanya (Buharman, 2002). Menurut Tinambunan (2006), hutan adalah suatu ekosistem berupa hamparan lahan berisi sumber daya alam hayati yang didominasi pepohonan dalam persekutuan alam lingkungannya, yang satu dengan yang lainnya tidak dapat dipisahkan. Sedangkan hutan kota adalah suatu hamparan lahan yang bertumbuhan pohon-pohon yang kompak dan rapat di dalam wilayah perkotaan baik pada tanah negara maupun tanah hak, yang ditetapkan sebagai hutan kota oleh pejabat yang berwenang (PP No. 63 Tahun 2002 tentang hutan kota Pasal 1 ayat 2 ). 
Menurut Samsoedin dan Waryono (2010) bentuk hutan kota secara umum adalah: (a) Jalur Hijau, (b) Taman Kota, (c) Kebun dan Halaman, (d) Kebun Raya, (e) Hutan Raya dan Kebun Binatang, dan (f) Hutan Lindung. Menurut Samsoedin dan Subiandono (2007) taman hutan raya atau disebut juga kebun raya merupakan pepohonan yang berdiri sendiri atau berkelompok atau vegetasi berkayu di kawasan perkotaan yang pada dasarnya memberikan dua manfaat pokok bagi masyarakat dan lingkungannya, yaitu manfaat konservasi dan manfaat estetika.

Perkembangan perekonomian dan pertumbuhan penduduk yang cenderung akan meminimalkan ruang terbuka hijau (RTH) yang pada akhirnya berdampak negatif terhadap keseimbangan ekosistem terutama di perkotaan. Perlu diketahui bahwa keberadaan taman hutan raya secara makro berfungsi mengurangi dampak dari efek rumah kaca, sedangkan secara mikro adalah untuk mengeliminasi dampak negatif dari pembangunan dan perkembangan perekonomian.

Untuk mengatasi hal tersebut keberadaan taman hutan raya merupakan salah satu solusi yang tepat dalam rangka mengeliminasi perubahan ekosistem. Hal ini sebagaimana ditegaskan dalam PP No. 63 Tahun 2002 Pasal 1 ayat 2 yang menyatakan keberadaan taman hutan raya ditetapkan oleh pejabat setempat yang berwenang. Secara umum pohon berperan untuk menyerap $\mathrm{CO}_{2}$ dan mengeluarkan $\mathrm{O}_{2}$, namun secara individu bahwa setiap jenis pohon mempunyai karakteristik dan fungsi yang berbeda seperti dalam hal estetika, menyerap polutan, meredam kebisingan, menyerap karbon, menyerap dan menepis bau tidak sedap, mengurangi bahaya hujan asam serta mengatasi genangan air.

Taman Hutan Raya Sultan Syarif Hasyim (Tahura SSH) merupakan kawasan pelestarian alam yang ditetapkan berdasarkan Surat Keputusan Menteri Kehutanan dan Perkebunan No. 348/KptsII/1999 tanggal 26 Mei 1999 seluas 6.172 ha. Kawasan Tahura SSH meliputi 3 kabupaten/kota yaitu Kabupaten Kampar seluas 3.041,81 ha, Kabupaten Siak seluas 2.323,33 ha dan Kota Pekanbaru seluas 806,86 ha. Berdasarkan hasil observasi dan wawancara dengan Bakti Rimbawan yang bertugas di Tahura Sultan Syarif Hasyim, diketahui bahwa luas tahura telah jauh berkurang dari luas sebelumnya. Diperkirakan luas tahura sekarang adalah \pm 2.300 ha, yang terdiri dari 800 ha di Kota Pekanbaru dan 1.500 ha di Kabupaten Siak. Sedangkan Kabupaten Kampar tidak memiliki lagi kawasan tahura. Hal ini dikarenakan seluruh wilayah tahura yang ada di wilayah Kabupaten Kampar telah beralih fungsi menjadi lahan perkebunan sawit.

Tahura SSH memiliki keragaman jenis flora yang cukup tinggi. Keanekaragaman jenis Tahura SSH sangat mewakili suatu kondisi hutan dengan tipe hutan hujan dataran rendah. Tercatat \pm 127 jenis flora yang merupakan tumbuhan asli hutan Tahura SSH yang didominasi dari family Dipterocarpaceae, Lauraceae, Euphorpeaceae, Anacardiaceae, Guttiferae, Sapotaceae, Myrtaceae dll (Dinas Kehutanan Provinsi Riau, 2015). Salah satu jenis pohon yang terdapat di Tahura SSH adalah pulai (Alstonia scholaris). Kayu pulai sangat prospektif untuk dikembangkan dalam pembangunan hutan tanaman karena manfaatnya yang cukup banyak dan saat ini permintaannya sangat tinggi. Salah satunya adalah kulit pulai yang dapat digunakan sebagai bahan obat-obatan (Effendi dkk., 2011). Tahura SSH memiliki peranan yang sangat penting untuk menjaga keberadaan pohon tersebut di masa yang akan datang agar tidak mengalami kepunahan. Akan tetapi, data mengenai pohon tersebut secara lengkap belum ada khususnya data mengenai kondisi densitas populasi pulai. Penghitungan densitas diperlukan sebagai salah satu parameter dalam deskripsi vegetasi.

\section{METODE PENELITIAN}

\section{A. Waktu dan Tempat}

Penelitian ini dilakukan di Taman Hutan Raya Sultan Syarif Hasyim Kota Pekanbaru, Jl. Yos Sudarso, Kota Pekanbaru. Penelitian ini dilakukan pada bulan Oktober - Desember 2017. 


\section{B. Alat dan Bahan}

Alat yang digunakan dalam penelitian ini adalah meteran untuk mengukur diameter pohon pulai, tally sheet Microsoft Excel untuk mencatat hasil pengukuran di lapangan, tali rafia untuk membuat batas plot pengamatan, dan kamera digital untuk mendokumentasikan kegiatan penelitian. Bahan yang digunakan dalam penelitian ini adalah pohon pulai (Alstonia scholaris) yang berada di Taman Hutan Raya Sultan Syarif Hasyim Kota Pekanbaru.

\section{Jenis Data}

\section{Data yang dikumpulkan meliputi data primer dan data sekunder.}

1. Data Primer

Data yang diperlukan adalah data densitas atau kerapatan dan DBH pohon pulai dewasa yang ada di Tahura SSH Riau.

2. Data Sekunder

Data yang dimaksud adalah peta Taman Hutan Raya Sultan Syarif Hasyim Riau, informasi masyarakat setempat, dan literatur yang berhubungan dengan penelitian ini

\section{Metode Pengumpulan Data}

1. Data Primer

Dari luas total \pm 2.300 ha, data dikumpulkan dengan membuat plot pengamatan dengan intensitas sampling $0,1 \%$. Luas sampel $8.000 \mathrm{~m}^{2}$ yang terdiri dari 20 plot pengamatan berukuran $20 \mathrm{~m}$ x $20 \mathrm{~m}$. Penentuan plot pengamatan dengan menggunakan metode simple random sampling.

\section{Data Sekunder}

Metode ini digunakan untuk mencari, menganalisis, mengumpulkan data penunjang yang terdapat dalam dokumen resmi seperti buku-buku, tulisan-tulisan umum, dan literatur lainnya yang berkaitan dengan penelitian.

\section{E. Prosedur Penelitian}

Adapun langkah kerja yang dilakukan dalam penelitian ini adalah sebagai berikut:

1) Membuat plot pengamatan.

2) Melakukan pengukuran yang mencakup densitas atau kerapatan, frekuensi, dan DBH pohon.

3) Data-data hasil pengukuran kemudian dimasukkan dalam lembar pengamatan (tally sheet) yang telah disediakan.

\section{F. Analisis Data}

Setelah data terkumpul, maka perlu dilakukan analisis data sebagai berikut:

1. Kerapatan (densitas)

Kerapatan (K) merupakan jumlah individu organisme per satuan ruang yang dapat dirumuskan sebagai berikut:
$\mathrm{K}=\frac{\text { jumlah individu }}{\text { luas petak contoh }}$

$$
\text { luas petak contoh }
$$

2. Frekuensi

Frekuensi (F) setiap jenis tumbuhan dihitung dengan rumus sebagai berikut:

$$
\mathrm{F}=\frac{\begin{array}{c}
\text { jumlah petak contoh } \\
\text { ditemukannya suatu spesies }
\end{array}}{\text { jumlah seluruh petak contoh }}
$$

\section{HASIL DAN PEMBAHASAN}

\section{A. Hasil}

Lokasi penelitian adalah Tahura Sultan Syarif Hasyim Kota Pekanbaru. Luas lokasi penelitian adalah \pm 800 ha. Penelitian dipusatkan pada 20 plot pengamatan yang masing-masingnya berukuran $20 \times 20 \mathrm{~m}$. Jarak antar plot pengamatan adalah $100 \mathrm{~m}$. Dari hasil pengukuran didapatkan 18 batang pohon pulai yang termasuk ke dalam 20 plot pengamatan.

1. Pengukuran Densitas (Kerapatan) dan Diameter Pohon Pulai (Alstonia scholaris)

Dari pengamatan yang dilakukan, didapatkan hasil sebagai berikut: 
Tabel 5.1 Diameter Batang dan Kerapatan Pohon Pulai (Alstonia scholaris)

\begin{tabular}{|c|c|c|c|}
\hline Plot & Keliling Batang (cm) & DBH $(\mathbf{c m})$ & $\mathbf{K}$ \\
\hline \multirow{3}{*}{1} & 100 & 31,84713376 & 0,0075 \\
\hline & 73 & 23,24840764 & \\
\hline & 89 & 28,34394904 & \\
\hline 2 & 93,4 & 29,74522293 & 0,0025 \\
\hline \multirow{3}{*}{3} & 150 & 47,77070064 & 0,005 \\
\hline & 98,6 & 31,40127389 & \\
\hline & 200,2 & 63,75796178 & 0,01 \\
\hline \multirow{3}{*}{4} & 88 & 28,02547771 & \\
\hline & 90,6 & 28,85350318 & \\
\hline & 115 & 36,62420382 & \\
\hline 5 & 145,7 & 46,40127389 & 0,0025 \\
\hline 6 & 0 & 0 & 0 \\
\hline 7 & 0 & 0 & 0 \\
\hline 8 & 98,3 & 31,30573248 & 0,0025 \\
\hline 9 & 78,2 & 24,9044586 & 0,0025 \\
\hline 10 & 90 & 28,66242038 & 0,0025 \\
\hline 11 & 0 & 0 & 0 \\
\hline 12 & 0 & 0 & 0 \\
\hline 13 & 0 & 0 & 0 \\
\hline 14 & 0 & 0 & 0 \\
\hline 15 & 0 & 0 & 0 \\
\hline 16 & 0 & 0 & 0 \\
\hline 17 & 0 & 0 & 0 \\
\hline 18 & 88 & 28,02547771 & 0,0025 \\
\hline \multirow{2}{*}{19} & 130,7 & 41,62420382 & 0,005 \\
\hline & 160 & 50,95541401 & \\
\hline 20 & 97,3 & 30,98726115 & 0,0025 \\
\hline
\end{tabular}

Dari Tabel 5.1 di atas diketahui bahwa kerapatan pohon pulai tertinggi berada pada plot pengamatan 4 dengan nilai kerapatan 0,01 atau 4 batang/ 400 $\mathrm{m}^{2}$. Sementara itu kerapatan terendah berada pada plot pengamatan $6,7,11$, $12,13,14,15,16$, dan 17 dengan nilai kerapatan 0 atau tidak ditemukan pohon pulai. Pada plot pengamatan $6,7,11$, dan 16 ditemukan beberapa pulai dalam tingkat pertumbuhan pancang (sapling).

Dari Tabel 5.1 di atas juga diketahui diameter pohon pulai terbesar yang diukur adalah $63,76 \mathrm{~cm}$ yang berada pada plot pengamatan 4 . Sedangkan diameter pohon pulai terkecil adalah $23,25 \mathrm{~cm}$ yang berada pada plot pengamatan 1. Rata-rata diameter pohon pulai dalam plot pengamatan adalah $35,12 \mathrm{~cm}$.

2. Pengukuran Frekuensi Pohon Pulai (Alstonia scholaris)

Frekuensi adalah jumlah petak contoh ditemukannya suatu spesies per jumlah seluruh petak contoh. Berdasarkan Tabel 5.1 diketahui terdapat 11 plot pengamatan ditemukannya pohon pulai. Jadi, 
Frekuensi $=$ jumlah petak contoh

$$
\begin{aligned}
& \text { ditemukannya suatu spesies } \\
& \hline \text { jumlah seluruh petak contoh } \\
& =11: 20 \\
& =0,55
\end{aligned}
$$

Frekuensi ditemukannya pohon pulai pada 20 plot pengamatan adalah 0,55 .

\section{B. Pembahasan}

Berdasarkan hasil penelitian diketahui bahwa sebaran pertumbuhan pohon pulai (Alstonia scholaris) tidak merata pada semua plot pengamatan. Terdapat 9 plot pengamatan yang tidak terdapat pohon pulai, tetapi ditemukan beberapa pohon pulai dalam tingkat pertumbuhan pancang (sapling). Berdasarkan informasi yang didapat dari Bakti Rimbawan yang bertugas di Tahura Sultan Syarif Hasyim bahwa jenis pulai yang tumbuh di tahura sebahagian adalah hasil penanaman kembali dan hanya sedikit yang tumbuh secara alami. Namun hasil penanaman kembali jenis pulai ini tidak semuanya berhasil sampai mencapai tingkat pertumbuhan pohon. Akibat kurangnya perawatan, maka banyak di antara bibit yang sudah ditanam tidak tumbuh dengan baik sehingga mati sebelum mencapai tingkat pertumbuhan pohon. Selain itu, banyak bibit yang ditanam di tanah kuning. Tanah kuning mengandung sedikit unsur hara yang diperlukan oleh tumbuhan untuk mendukung kehidupannya. Tumbuhan yang ditanam di tanah seperti ini tidak akan bisa tumbuh dengan baik.

Kerapatan (densitas) total pohon pulai di Tahura Sultan Syarif Hasyim adalah 18 batang/ $8000 \mathrm{~m}^{2}$ atau 18 batang/ 0,8 ha. Nilai kerapatan ini hampir sama jika dibandingkan dengan kerapatan pulai di Tahura Wan Abdul Rachman, Bandar Lampung yaitu 15 batang/ ha (Siahaan, Indriyanto, dan Setiawan, 2015). Rata-rata diameter pohon pulai dalam plot pengamatan adalah 35,12 cm. Pertumbuhan diameter batang pohon sangat dipengaruhi oleh lingkungan tempat tumbuh pohon tersebut. Pohon pulai yang tersebar di seluruh
Indonesia umumnya tumbuh pada daerah dengan ketinggian $0-1.000$ mdpl dengan intensitas curah hujan $1.000-3.800 \mathrm{~mm} / \mathrm{th}$. Pohon yang dipanen dalam kurun waktu 10 12 tahun dengan diameter $30-40 \mathrm{~cm}$ dan tinggi batang bebas cabang $10-14 \mathrm{~m}$, merupakan jenis cepat tumbuh (fast growing). Secara geografis tahura terletak antara $00^{\circ} 38^{\prime} \mathrm{s} / \mathrm{d} 00^{\circ} 44^{\prime}$ Lintang Utara dan $101^{\circ} 27^{\prime} \mathrm{s} / \mathrm{d} 101^{\circ} 27^{\prime}$ Bujur Timur, dengan kelerengan (9\% -15\%) dan ketinggian antara \pm 10 meter s/d 100 meter dari permukaan laut. Kondisi geografis tahura yang cocok dengan syarat tumbuh pohon pulai merupakan salah satu faktor yang dapat menyebabkan pohon pulai dapat tumbuh dengan baik.

Frekuensi pohon pulai pada Tahura Sultan Syarif Kasim adalah 0,55. Terdapat 11 petak contoh ditemukannya pohon pulai di antara total 20 petak contoh pengamatan. Nilai ini lebih tinggi dibandingkan dengan frekuensi pohon pulai pada Tahura Wan Abdul Rachman yaitu 0,20. Hal ini menandakan pertumbuhan pohon pulai di Tahura Sultan Syarif Hasyim lebih menyebar dibandingkan Tahura Wan Abdul Rachman.

\section{KESIMPULAN DAN SARAN}

\section{A. Kesimpulan}

Berdasarkan hasil penelitian dan pembahasan dapat disimpulkan:

1. Kerapatan (densitas) pohon pulai (Alstonia scholaris) di Tahura Sultan Syarif Hasyim Kota Pekanbaru adalah 18 batang/ 0,8 ha.

2. Diameter rata-rata pohon pulai (Alstonia scholaris) di Tahura Sultan Syarif Hasyim Kota Pekanbaru adalah 35,12 $\mathrm{cm}$.

\section{B. Saran}

Saran yang berkenaan dengan penelitian ini adalah:

1. Fungsi Tahura Sultan Syarif Hasyim tetap terjaga sebagai salah satu kawasan konservasi yang ada di Kota Pekanbaru. 
2. Dilakukan penelitian lebih lanjut mengenai kerapatan pohon pulai di Tahura Sultan Syarif Hasyim Kabupaten Siak.

\section{DAFTAR PUSTAKA}

Abdullah. 2010. Inventarisasi Jenis-Jenis Tumbuhan Berkhasiat Obat Di Hutan Hujan Daratan Rendah Desa Nyamplung Pulau Karimun Jaya. http://www.Jurnal of Biosaintifikasi. Vol.2.No.2, September 2010. ISSN 208-191X,Hal 75-81. Diakses tanggal 23 febuari 2014.

Arinana, A. Dan F. Diba. 2009. Kualitas Kayu Pulai (Alstonia scholaris) Terdensifikasi (Sifat Fisis, Mekanis dan Keawetan). ResearchGate. Diakses: 02 Januari 2018.

Dinas Kehutanan Provinsi Riau. 2015. Taman Hutan Raya Sultan Syarif Hasyim Provinsi Riau. http://dinaskehutanan.riau.go.id/tamanhutan-raya-sultan-syarif-hasyimprovinsi-riau/. Diakses: 13 September 2017.

Effendi, R., A. Hafsari, dan Zuraida. 2011. Kajian Tata Niaga Kulit Pulai (Alstonia scholaris) sebagai Bahan Baku Obat Hipertensi (Antihipertensi) di Provinsi Jawa Tengah. Jurnal Penelitian Hutan Tanaman. 8(5) : 315321.

Fakhrozi, I. 2009. Etnobotani Masyarakat Suku Melayu Tradisional di Sekitar Taman Nasional Bukit Tigapuluh: Studi Kasus Di Desa Rantau Langsat, Kec. Batang Gangsal, Kab. Indragiri Hulu, Provinsi Riau. Departemen Konservasi Sumber Daya Hutan dan Ekowisata Fakultas Kehutanan Institut Pertanian Bogor. Bogor.

Hamzari. 2008. Identifikai Tanaman ObatObatan yang Dimanfaatkan oleh
Masyarakat Sekitar Hitan Tabo-Tabo. Jurnal Hutan dan Masyarakat Universitas Talulako.

Khare C.P. 2007. Indian Medicinal Plants: An Illustrated Dictionary. SpringerVerlag Berlin/Heidelberg (2007) 3839.

Kriswiyanti, E., 2007. Eksplorasi Bahan Obat Tradisional Bali Berdasarkan Kajian Usada dalam KegiatanPendataan dan Identifikasi Bahan Obat Tradisional Bali. Laporan Penelitian Pengembangan BidangIlmu dan Teknologi Dasar. Jurusan Biologi, Fakultas MIPA Universitas Udayana.

Tudjuki K., S. Ningsih, B. Toknok. 2014.

Keanekaragaman JenisTumbuhan Obat pada Kawasan Hutan Lindung di Desa Tindoli Kecamatan Pamona Tenggara Kabupaten Poso. Jurnal Warta Rimba. Vol.2. No.1. Juni 2014.

Rosanti, D. 2013. Morfologi Tumbuhan. Erlangga. Jakarta Tjitrosoepomo, G. 2010. Taksonomi Tumbuhan (Spermatophyta). Gadjah Mada Universitas Press. Yogyakarta.

Siahaan, A. A. J., Indriyanto, dan A. Setiawan. 2015. Densitas Pohon Dewasa dan Permudaan Pulai (Alstonia Scholaris) dan Suren (Toona Sureni) dalam Blok Koleksi Tumbuhan di Taman Hutan Raya Wan Abdul Rachman. Jurnal Sylva Lestari. Vol. 3 No. 1, Januari 2015 (91-102).

World Agroforestry. 2009. Alstonia scholaris.

http://www.worldagroforestry.org/tree db/AFTPDFS/Alstonia_scholaris.PDF. Diakses: 13 September 2017.

Zuhud., AM. Ervizal. 2008. Potensi Hutan Tropika Indonesia Sebagai Penyangga Bahan Obat Alam Untuk Kesehatan Bangsa. Fakultas Kehutanan IPB. Bogor. 